\title{
OCCUPATIONAL CONTACT DERMATITIS IN
}

\section{CAR REPAIR WORKERS AT THE INDUSTRIAL ZONE IN ZAGAZIG CITY}

\author{
By \\ El-Laithy N.; Attwa E.*; Sabik L.M.E.**; and Nomier M.A.** \\ FROM \\ Departments of Community, Environmental, and Occupational Medicine, Dermatology and \\ Venereology* and Forensic Medicine and Clinical Toxicology**, \\ Faculty of Medicine, Zagazig University.
}

\begin{abstract}
Background: Occupational contact dermatitis (OCD) is a common skin disorder with a poor prognosis, resulting in a noteworthy economic impact for society \& for an individual and amenable to public health interventions. Objectives: 1) determining the prevalence of contact dermatitis(CD)among car repair workers. 2) studying some risk factors associated with $\mathrm{CD}$ and 3) Conducting an intervention skin care education program to control this problem and evaluate its impact on knowledge, attitude, symptoms and signs of CD. Subjects and methods: 1- A comparative cross-sectional study was conducted on 87 car repair workers (29 car tinkers, 29 car mechanics and 29 car painters) with regular and direct exposure to chemical materials at the Industrial Zone in Zagazig City and non-exposed control group consisted of 76 booksellers. All workers were subjected to questionnaire, clinical examination and those who diagnosed clinically as CD were patch-tested. 2- Intervention study with a skin care education program was carried out on 47 car repair workers. Re-evaluation of the intervention group was done after 5 months as regard knowledge, attitude, symptoms and signs of CD. Results: The total prevalence of CD among car repair workers(18.4\%)
\end{abstract}


was significantly higher compared to their controls(3.9\%), with the highest prevalence among car mechanics $(24.1 \%)$, and car painters $(20.7 \%) .16 .1 \%$ of car repair workers reported recurrent dermatitis in the last 12 months. The most commonly affected areas were the fingers, webs and hands(81.3\%). $40 \%$ of car repair CD cases found to have allergic $\mathrm{CD}$ and $60 \%$ have irritant $\mathrm{CD}$. Nickel accounted for most positive patch test reactions (33.3\%). Hammering, friction with repaired parts and sanding of painting parts with cementing the car body with pastes were the most important procedures at the workplace that start and worsen $\mathrm{CD}$ cases. The young car repair workers, who smoke and with past history of atopy had a significant high risk to develop CD. After the intervention study, a significantly higher knowledge level about $\mathrm{CD}$ causes, risk factors, prevention, with change in the attitude and behavior of workers and decreased in the reported symptoms and signs of CD.

Conclusion and recommendations: Car repair workers are at high risk for OCD, irritant as well as allergic, due to exposure to various chemicals at work. Young age, smoking, atopy and duration of work are found to be risk factors for CD. Skin care education program is an important tool for primary prevention of $\mathrm{CD}$ and control of exposure to substances hazardous to the skin. More long-term large-scale studies are needed to confirm further the cost-effectiveness of this and other skin protection programs.

\section{Introduction}

Occupational skin diseases constitute up to $30 \%$ of all occupational diseases $(1,2)$, as the skin is a major organ and direct target for metal-working and industrial chemicals that can produce toxicological manifestations ranging from acute irritation to proliferation and tumor forma$\operatorname{tion}^{(3)}$.

Occupational dermatoses are mostly affect young people, expensive to the society (only in UK, workers cost estimated between L24 million and L59 million in $1995 / 6)^{(4,5)}$, disabling(6), with payable compensation $^{(2)}$ and were reported to be an important predictor for long term unemployment $^{(7)}$. The most common work related dermatoses is contact dermatitis $(8,9)$ which is one of the leading causes of occupational morbidity and absenteeism, as it ranks, in many countries, the first or the highest amongst all notified occupational diseases and become an intolerable cause of missed workdays and even loss of occupation $^{(1,8,10,11,12)}$. 
Occupational contact dermatitis(OCD) is a pathological condition where there is a pattern of inflammatory response of the skin that occurs as a result of contact with external factors(allergens, irritants) present in an occupational setting and can be influenced by a combination of exposure characteristics exposure to wet work, friction, handling of chemicals and working practices (exogenous factors)\} as well as individual susceptibility (endogenous factors) $(8,10,13,14)$ and its severity depend on the type and intensity of exposure(10).

There are two types of contact dermatitis:, irritant (ICD) and allergic contact dermatitis(ACD). ICD is the most common type ${ }^{(9,10)}$ and occurs after exposure to an agent or agents causing early impairment and then cumulative damage to the stratum corneum. ACD is a manifestation of a type IV hypersensitivity reaction which develops at the site of skin contact with the allergen and may spread to previously unexposed sites ${ }^{(15,16)}$.

High risk occupations as mechanics, car painters and vehicle maintenance men are exposed to irritant chemicals as organic solvents(17), various oils and allergens as rubber, nickel ${ }^{(18)}$ and metal-working fluids capable of causing irritant and allergic contact dermatitis $(10,19)$.
Epidemiological studies investigating the risk of occupational skin disease have been performed in car factories ${ }^{(20)}$ but little have been done on car repair workers doing repair jobs especially car tinkers and car mechanics.

As patients with OCD have a poor prognosis for clearing their skin diseases (10), worker education is an important determinant of OCD cases outcome even after complete evaluation of the worker and specific antigen avoidance ${ }^{(11)}$. So occupational intervention studies are needed to improve the health of the workers and to see if it is possible to improve working conditions and to what extent.

So, this study was conducted to: 1) determine the prevalence of $\mathrm{CD}$ among car repair workers. 2) study some risk factors associated with $\mathrm{CD}$ and 3) Conduct an intervention skin care education program to control this problem and evaluate its impact on knowledge, attitude, symptoms and signs of $\mathrm{CD}$ among car repair workers.

\section{Subjects and Methods}

\section{Study setting and job description:}

This study had been carried out in the period from September 2006 to August 2007 in car repair shops at the Industrial 
Zone in Zagazig City. Inside these shops, the workers are responsible for repairing damaged or defected cars as follow:-

- In car tinker shops, the worker's activities include hammering and welding, where they use epoxy resin paste as adhesive

- In car mechanic shops, the car mechanics repair any defects in the car engine. During their activities, they use gasoline, benzene as solvents, epoxy resin as adhesive, and engine oils, which are used for maintenance of car engine as it reduce friction, adhesion or welding.

- In car painters shops, car painters are responsible for small paint jobs or spray painting of the whole car. Abrasive blasting with sand that contains crystalline silica is used for paint removal. After the cars have been cemented with pastes(masking), spray painting is done in the form of base coat, color coat and clear coat. During their activities, they use gasoline, benzene, alcohol \& acetone as solvents, epoxy and polyester resins as cements to produce a smooth surface before the final spray painting.

\section{Study design:}

The study was done in two stages:-
1- A comparative cross-sectional study was first conducted among a sample of 87 car repair workers and 76 booksellers to estimate the prevalence of contact dermatitis among them.

2- Intervention study was carried out, in which an intervention group of 47 car repair workers was exposed to a skin care education program.

\section{Sample size:}

The size of the study sample was 87 , calculated using Epi-info program version 6.1 (21); with total number of 137 car repair workers working in 60 car repair shops as estimated by the City Council, $70 \%$ power of the test, $95 \%$ confidence interval and $15.3 \%$ prevalence of contact dermatitis among car repair shop workers as estimated from previous studies ${ }^{(22)}$.

\section{Study workers selection:}

1- Car repair workers (exposed group): by a simple random sample, a total number of 87 male car repair workers composed of 29 car tinkers, 29 car mechanics and 29 car painters, with regular and direct exposure to chemicals, were selected and included in this study.

2-Control group: included 76 male booksellers worked at the book shops in 
Zagazig City, had no history of occupational exposure to chemical agents were selected randomly and matched the exposed group as regards age, educational leved study was voluntary and all participants gave informed consent.

\section{Methods}

1-Questionnaire: All workers were interviewed using a questionnaire prepared from Nordic Occupational Skin Questionnaire ${ }^{(23)}$ with modified and additional questions on knowledge, attitude and practice regarding exposure, preventive measures, and discussions on prevention of skin problems.

Pilot study: The constructed questionnaire was piloted on a sample of workers to check the acceptability of the questions. This resulted in some minor alternations to a few of the questions set. It includes:

a- Personal history: it included age, educational level, and smoking habit .

b-Occupational history: it included current job, activities at work especially chemicals or materials handling in the work and its composition if possible, duration of employment in years, uses of protective clothes, and previous, another jobs, or activities outside work in which there was exposure to any chemicals. c- History of atopic symptoms as atopic rhinitis, asthma and dermatitis.

d- Self-reported skin symptoms of CD within the last 12 months and at the time of the study, with its location, and timing .

e- Exacerbating factors: especially about certain chemicals, important things or anything else in the work makes the skin symptoms worse, and its improvement at the weekends.

f- Hand washing frequency using water or soaps containing scrubbing particles with use of various agents in cleaning their hands as organic solvents.

Those workers with history of previous, other jobs, or other activities outside work in which there were exposure to any chemicals were excluded from the study

2-Clinical examination: All workers were examined for signs of contact dermatitis as redness, vesiculations, ulcers, dryness, pigmentation and swelling and its sites.

\section{Diagnosis of OCD:}

Evidence to support the diagnosis of occupational dermatitis depends on the following well-recognized indicators:

- Occupational contact with an agent known to cause similar skin changes in other individuals. 
- The occurrence of similar dermatitis in fellow workers within the same occupation.

- A time relationship between exposure and dermatitis.

- Type and site of lesions consistent with occupational exposure.

- Similarity to other post-exposure episodes of dermatitis followed by an improvement and resolution after removal ${ }^{(1)}$. This is also assessed by a detailed history and examination by a dermatologist corroborated by patch tests results.

\section{3- Patch testing:}

Nevertheless, as morphologic characteristics of allergic and irritant contact dermatitis are similar(24), only application of diagnostic patch tests could have ruled out with certainty the presence of allergic contact dermatitis. Patch testing is required to identify the external chemicals to which the worker is allergic and it is most cost effective and reduces the cost of therapy in patients with severe $\mathrm{ACD}^{(25)}$.

Patch testing procedure : 10 from 16 workers diagnosed clinically as $\mathrm{CD}$ and agreed to participate in this procedure(5 car mechanics, 4 car painters and one car tinker)were prone to the standard patch test (TRUE Test) by a dermatologist, after controlling of the disease clinically for at least 2 weeks following the acute phase.

Exclusion criteria were systemic or local corticosteroid or immunosuppressive treatment, immuno-compromize disease florid eczema or UV exposure in the tested area.

The TRUE Test used in this study manufactured by (Mekos Laborations A/S, Hillersd, Denmark), is supplied in multipack cartons of 10 standard tests. The test consists of 2 panels (I and II) each one containing 12 allergens in a prearranged sequence. The panels were applied simultaneously on the left and the right side of the upper back, a $5 \mathrm{~cm}$ wide area of skin on either side of the midline(Fig.1). With a medical marking pen, the location of the two notches on each panel was indicated. Patches were removed at $48 \mathrm{~h}$, and readings were made at 49 and 72-96 $\mathrm{h}$ following the initial application ${ }^{(25)}$. All readings were performed by the same investigator according to the system suggested by the International Contact Dermatitis Research Group (ICDRG) in 1970(26). Readings were classified as negative, allergic, doubtful and irritant. Presumed allergic reactions were graded as + (erythema, infiltration and possible papules), ++ (erythema, 
infiltration, papules and vesicles) or +++ (erythema, infiltration and coalescent vesicles). A reaction was interpreted as doubtful when only long-lasting erythema without infiltration was present or when an erythematous infiltrated reaction covered $50 \%$ or less of the tested area. Irritant reactions defined as weak, macular erythema without infiltration or as a follicular pattern restricted to the area covered by the chamber .

Subjects with a positive patch test reaction to one or more tested contact allergens were considered to have contact sensitization $^{(27)}$, while cases with a history of exposure to irritants \& periods of eczema related in time to such exposure, and when no other diagnosis present, were irritant CD.

Testing to more allergens increases accuracy of the diagnosis of $\mathrm{ACD}^{(16)}$.

4- Intervention study: This intervention study was carried out on a group of 47 car repair workers, who agreed to participate in this study including those who clinically diagnosed as CD. This intervention group was exposed to a skin care education program

Intervention skin care education program:
A skin care education program is a series of practical instructions about skin care directed at car repair workers for a period of 5 months. It is an integrated part of an educational program. It includes:-

a- Health education: through face to face approach including data about:

1- Skin, healthy or diseased and dermal effects of contacts with chemicals especially dermatitis(definition, risk factors, clinical picture, complications and treatment).

2- Importance of personal cleanliness in the prevention of dermatitis. Workers must have access facilities for washing hands inside their shops with frequent hand washing that will reduce the risk of chemicals and prevent CD. It is also important to note that excessive hand washing with cleansers or detergents can dry out and damage the skin and to know that washing with more easily available industrial detergents can be harmful to the skin.

3- The proper use of personal protective gloves, aprons, overalls, and clothing will minimize contact with harmful agents. Also contaminated clothes with chemicals should always laundered before they are worn again.

b-Skin care provision: included sup- 
plementation of gloves, barrier cream and paper towel provision.

c- Treatment of cases: by a dermatological consultant. It included:

1-Topical treatments included emollients, corticosteroid creams /ointments.

2-Systemic treatments included oral corticosteroids in short treatment courses, azathioprine , methotrexate(MTX), cyclosporine and retinoids.

Re-evaluation of the intervention group after 5 months as regard knowledge, attitude, and symptoms was done by using the same starting questionnaire and underwent clinical examination of their hands to assess the intervention program effect.

\section{Data management and analysis:}

The collected data were computerized and statistically analyzed using SPSS (Statistical Package for Special Sciences) program for windows (version 11.0)(28). The qualitative data were evaluated using chisquared $\left(\chi^{2}\right) \&$ Fisher exact tests and McNemar's test for paired analysis, while student's t-test was used for comparison between quantitative data. Odds ratios(ORs) and their $95 \%$ confidence intervals $(95 \%$ CI) were calculated. The significance level was considered at $\mathrm{P}$-value $<0.05$.

\section{Results}

Table (1) shows that, there were no significant differences between car repair workers and their controls regarding age, educational level, smoking habit, and duration of work.

Table (2) demonstrates that, the total prevalence of OCD among car repair workers $(18.4 \%)$ was significantly $(\mathrm{P}<0.01)$ higher when compared to their control booksellers. Also when the three investigated jobs in this study are considered, there are substantial differences. Car mechanics and car painters had a significant high risk to develop OCD $\{\mathrm{OR}$ (95\%CT), 7.74(1.57-49.07) \& 6.35 (1.21-41.43) respectively\} more than car tinkers \{OR (95\%CT), 2.81(0.35-22.06) when compared to their controls. The highest prevalence of contact dermatitis was significantly detected among car mechanics $(24.1 \%$ \& $\mathrm{P}<0.001)$, and car painters $(20.7 \%$ \& $\mathrm{P}<0.01$ ), while the lowest prevalence (10.3\%) was non-significantly detected among car tinkers when compared to their controls (3.9\%).

Table (3) shows that, most diagnosed cases were presented with slight fissures, erythema and pruritis and most of the workers reported having 2 or more skin 
symptoms at baseline. Also the prevalence of most symptoms and signs of $\mathrm{CD}$ was significantly higher among car repair workers when compared to their controls $(\mathrm{P}<0.05)$, while there were no significant differences between them as regard to ulcers and pigmentation $(\mathrm{P}>0.05)$ and most of symptoms of $\mathrm{CD}$ in car repair workers vocations. $16.1 \%$ of car repair workers (constituted $87.5 \%$ of CD cases) reported recurrent dermatitis in the last 12 months, while only one of their controls did so.

The most commonly affected areas with $\mathrm{CD}$ among car repair workers were in the fingers, webs and hands(81.3\%) (Fig.2), the wrist \& forearm (31.1\%) and other sites(under the shoulder, popliteal \& cubital fossae) (12.5\%) .

The results of this study also showed that, $28(32.2 \%)$ of car repair workers had skin symptoms within the last 12 months and $9(10.3 \%)$ reported history of childhood eczema. Also, on clinical examination, $39(44.8 \%)$ of car repair workers especially car tinkers $\{17(58.6 \%)\}$ had dry skin on their hands without dermatitis and $5(5.7 \%)$ had other skin diseases(tinea, pruritis and psoriasis). Most car mechanics and painters wash their hands with gasoline or benzene but, no body in the study was wearing protective gloves or using barrier creams or emollients, except few workers wear protective aprons.

Table (4) shows that, the majority of car repair workers with $\mathrm{CD}(60.0 \%)$ were ICD, while 4 workers $(40.0 \%)$ had positive patch test(ACD).

Table (5) shows the results of standard patch (TRUE) test. The number of positive reaction exceeded the number of positive patients because the 4 patients had more than one positive reaction. Nickel sulphate accounted for most positive patch test reactions $3 / 9$, followed by colophony $2 / 9$, epoxy resin 2/9, potassium dichromate $1 / 9$, and p-phenylenediamine 1/9 in both car mechanics and painters. The only car tinker CD case who patch-tested was found to have irritant reaction to nickel sulphate. Also $60 \%$ of cases have ICD to other substances who exposed to them during their work and not included in the standard patch test.

Table (6) shows that the most important procedures \& things at the workplace that start and worsen CD cases were hammering in car tinkers (100.0\%), friction with repaired parts, tar and engine oils in car mechanics(85.7\%), sanding of painting parts $(83.3 \%)$ and cementing the car body with pastes (masking) (66.7\%) in car 
painters respectively. While other aggravating factors at the workplace like wetness, frequent washing the hands with solvents and friction of the hands with anything were also from the important things that worsen $\mathrm{CD}$ cases in car mechanics(57.0\%) and car painters (50.0\%) respectively.

Table (7) shows some risk factors associated with $\mathrm{CD}$ where younger car repair workers, who smoke, with past \& family histories of atopy and work for more than 10 years had a significant high risk to develop $\mathrm{CD}$ when compared with older ones, non smokers, without past \& family histories of atopy, and those who work for 10 years or less respectively \{OR $(95 \% \mathrm{CI})$, 3.87 (1.03-17.82), 3.59 (1.00-14.44), 7.61 $(1.36-43.39), \quad 4.92(1.00-22.88)$ and 3.81
(1.06-15.35) respectively\}.

Table (8) revealed a significantly higher knowledge level regarding CD definition, causes, risk factors, and prevention among car repair workers after the intervention study. Also a significant change in the attitude and behavior of car repair workers after the intervention program, evidenced by good health seeking behavior in the form of safe work practice, and skin care with significant increased in the number of workers using protective gloves.

Table (9) shows a significant reduction in the number of car repair workers who suffering from symptoms and signs of $\mathrm{CD}$ with significant decreased in the number of workers who complained from recurrent dermatitis after the intervention program. 
Table(1): Demographic and occupational characteristics of the studied groups.

\begin{tabular}{|lc|c|c|c|}
\hline \multicolumn{2}{|c|}{ Characteristics } & $\begin{array}{c}\text { Car repair } \\
\text { workers } \\
\mathrm{N}=87\end{array}$ & $\begin{array}{c}\text { Control group } \\
\mathrm{N}=76\end{array}$ & P- value \\
\hline Age (Y) & $(\overline{\mathrm{X}} \pm \mathrm{SD})$ & $33.7 \pm 11.2$ & $32.8 \pm 6.7$ & $>0.05$ \\
\hline Education:- & & $7(8.1)$ & $4(5.3)$ & \\
-Illiterate: & $\mathrm{N}(\%)$ & $29(33.3)$ & $16(21.1)$ & $>0.05$ \\
-Read \& write: & $\mathrm{N}(\%)$ & $43(49.4)$ & $40(52.6)$ & \\
-School & $\mathrm{N}(\%)$ & $8(9.2)$ & $16(21.1)$ & \\
-High & $\mathrm{N}(\%)$ & $38(43.7)$ & $30(39.5)$ & $>0.05$ \\
\hline Smokers & $\mathrm{N}(\%)$ & $15.1+9.6$ & $13.3+9.3$ & $>0.05$ \\
\hline \multicolumn{2}{l|l}{ Duration of work $(\overline{\mathrm{X}} \pm \mathrm{SD})$} & & \\
\hline
\end{tabular}

Table (2): Distribution of contact dermatitis among the studied workers.

\begin{tabular}{|l|c|c|c|}
\hline \multicolumn{1}{|c|}{ Studied workers } & Total & $\begin{array}{c}\text { Prevalence of CD } \\
\mathrm{N}(\%)\end{array}$ & OR (95\% CI) \\
\hline Control group (Booksellers) & 76 & $3(3.9)$ & 1.0 \\
\hline Car repair workers & 87 & $16(18.4)$ & $5.48(1.46-30.35)^{* *}$ \\
\hline Car tinkers & 29 & $3(10.3)$ & $2.81(0.35-22.06)$ \\
\hline Car mechanics & 29 & $7(24.1)$ & $7.74(1.57-49.07)^{* *}$ \\
\hline Car painters & 29 & $6(20.7)$ & $6.35(1.21-41.43)^{*}$ \\
\hline
\end{tabular}

$* \mathrm{P}<0.01 \quad * * \mathrm{P}<0.001$ 
Table (3): Distribution of symptoms, signs and site of contact dermatitis among studied workers.

\begin{tabular}{|c|c|c|c|c|c|}
\hline \multicolumn{2}{|c|}{$\begin{array}{c}\text { Symptoms \& signs of contact } \\
\text { dermatitis }\end{array}$} & $\begin{array}{c}\text { Car repair } \\
\text { workers } \\
\mathrm{N}=87\end{array}$ & $\begin{array}{c}\text { Control } \\
\text { group } \\
\mathrm{N}=76\end{array}$ & $\bar{\chi}^{2}$ & P-value \\
\hline \multicolumn{2}{|l|}{ Symptoms: } & & & & \\
\hline -Pain \& redness: & $\mathrm{N}(\%)$ & $10(11.5)$ & $2(2.6)$ & 4.67 & $<0.05$ \\
\hline -Itching & $\mathrm{N}(\%)$ & $12(13.8)$ & $2(2.6)$ & 6.44 & $<0.01$ \\
\hline -Oedema & $\mathrm{N}(\%)$ & $7(8.1)$ & $0(0.0)$ & Fisher exact & $<0.05$ \\
\hline -Ulcers & $\mathrm{N}(\%)$ & $3(3.4)$ & $0(0.0)$ & Fisher exact & $>0.05$ \\
\hline \multicolumn{2}{|l|}{ Signs: } & & & & \\
\hline -Erythema & $\mathrm{N}(\%)$ & $10(11.5)$ & $2(2.6)$ & 4.67 & $<0.05$ \\
\hline -Vesicles & $\mathrm{N}(\%)$ & $8(9.2)$ & $1(1.3)$ & Fisher exact & $<0.05$ \\
\hline -Fissures & $\mathrm{N}(\%)$ & $10(11.5)$ & $1(1.3)$ & 6.68 & $<0.01$ \\
\hline -Crust & $\mathrm{N}(\%)$ & $6(6.9)$ & $0(0.0)$ & Fisher exact & $<0.05$ \\
\hline \multicolumn{2}{|l|}{-Lichenification } & & & & \\
\hline \& Dryness & $\mathrm{N}(\%)$ & $9(10.3)$ & $1(1.3)$ & Fisher exact & $<0.05$ \\
\hline -Pigmentation & $\mathrm{N}(\%)$ & $3(3.4)$ & $0(0.0)$ & Fisher exact & $>0.05$ \\
\hline -Ulcers & $\mathrm{N}(\%)$ & $2(2.3)$ & $0(0.0)$ & Fisher exact & $>0.05$ \\
\hline Recurrent CD & $\mathrm{N}(\%)$ & $14(16.1)$ & $1(1.3)$ & 10.6 & $<0.001$ \\
\hline \multirow{2}{*}{\multicolumn{2}{|c|}{$\begin{array}{l}\text { Site of CD: } \\
\text {-Fingers, the }\end{array}$}} & & & & \\
\hline & & $\mathrm{N}=16$ & $\mathrm{~N}=3$ & & \\
\hline hands & $\mathrm{N}(\%)$ & $13(81.3)$ & $2(66.7)$ & & \\
\hline \multicolumn{2}{|c|}{-Wrists \& Forearms N(\%) - } & $5(31.1)$ & $0(0.0)$ & & \\
\hline Other sites & $\mathrm{N}(\%)$ & $2(12.5)$ & $2(66.7)$ & & \\
\hline
\end{tabular}


Table (4): Distribution of CD cases according to results of patch test among car repair workers.

\begin{tabular}{|l|c|c|c|}
\hline \multicolumn{1}{|c|}{$\begin{array}{c}\text { Patch test } \\
\text { results }\end{array}$} & $\begin{array}{c}\text { workers } \\
\mathrm{C} \mathrm{D} \\
\mathrm{N}=10\end{array}$ & $\mathrm{NCD}$ & $\mathrm{N}(\%)$ \\
\hline Car tinkers & $\mathrm{N}=1$ & $0(0.0)$ & $\mathrm{N}(\%)$ \\
\hline Car mechanics & $\mathrm{N}=5$ & $2(40.0)$ & $3(100.0)$ \\
\hline Car painters & $\mathrm{N}=4$ & $2(50.0)$ & $2(50.0)$ \\
\hline Car repair workers & $\mathrm{N}=10$ & $4(40.0)$ & $6(60.0)$ \\
\hline
\end{tabular}

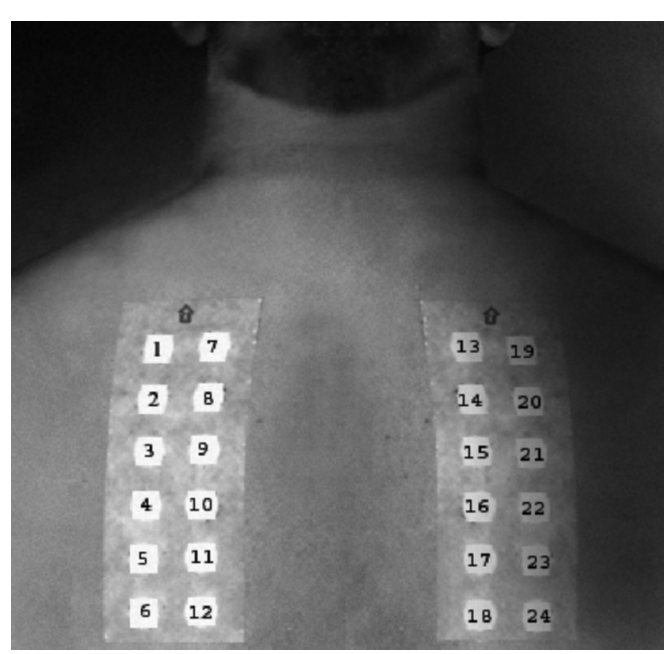

Fig.(1): Method of TRUE Test application

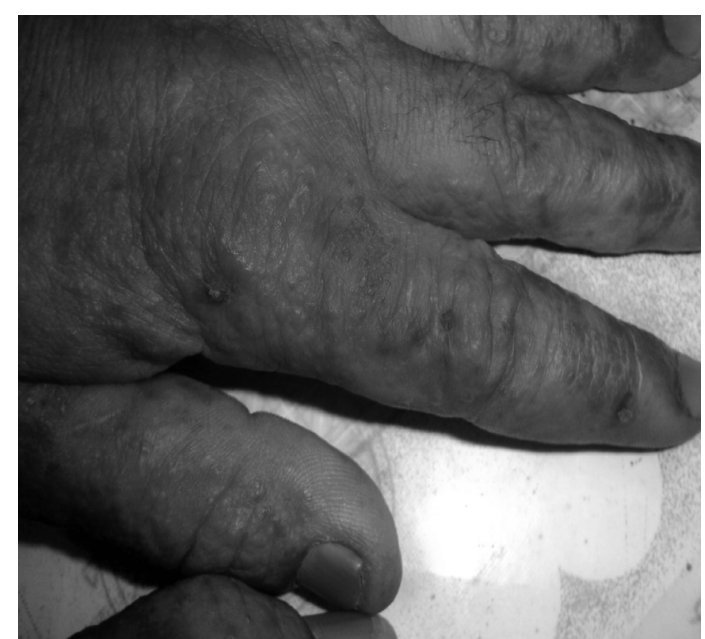

Fig.(2):CD in the hand of car mechanic. 
Table (5): Results of standard (TRUE) patch test among the car repair workers as regard the type of reaction.

\begin{tabular}{|c|c|c|}
\hline Allergen & $\begin{array}{c}\text { Workers with positive } \\
\text { patch test* }(\mathrm{N}=5) \\
\text { No } \quad(\text { Worker })\end{array}$ & Type of reaction \\
\hline Nickel sulfate & $\begin{array}{lc} & \text { (car tinker) } \\
1 & \text { (car mechanics) } \\
2 & \text { (car painter) } \\
1 & \end{array}$ & $\begin{array}{c}\mathrm{IR} * * \\
++,++ \\
+\end{array}$ \\
\hline \multicolumn{3}{|l|}{ Lanolin alcohol } \\
\hline Neomycin & (car painter) & \\
\hline Potassium dichromate & 1 & +++ \\
\hline \multicolumn{3}{|l|}{ Caine mix } \\
\hline Fragrance mix & (car painter) & \\
\hline Colophonium & (car mechanic) & +++ \\
\hline Epoxy resin & (car painter) & + \\
\hline Quinoline mix & (car mechanic) & ++ \\
\hline $\begin{array}{l}\text { Balsam of Peru (Myroxylon } \\
\text { pereirae resin) }\end{array}$ & 1 & + \\
\hline \multicolumn{3}{|l|}{ Ethylenediamine } \\
\hline \multicolumn{3}{|l|}{ Cobalt } \\
\hline \multicolumn{3}{|l|}{$\begin{array}{l}\text { p-tert-butylphenol- } \\
\text { formaldeyde resin }\end{array}$} \\
\hline \multicolumn{3}{|l|}{\begin{tabular}{|l|} 
Paraben mix \\
\end{tabular}} \\
\hline \multicolumn{3}{|l|}{ Carba mix } \\
\hline \multicolumn{3}{|l|}{ Black rubber mix } \\
\hline \multicolumn{3}{|l|}{$\mathrm{MCI} / \mathrm{MI}$} \\
\hline \multicolumn{3}{|l|}{ Quaternium-15 } \\
\hline MBT & (car painter) & \\
\hline PPD & 1 & + \\
\hline \multicolumn{3}{|l|}{ Formaldehyde } \\
\hline \multicolumn{3}{|l|}{ Mercapto mix } \\
\hline \multicolumn{3}{|l|}{ Thimerosal } \\
\hline Thiuram mix & & \\
\hline
\end{tabular}

$\mathrm{MCI} / \mathrm{MI}=$ methylchloroisothiazolinone/methylisothiazolinone;

$\mathrm{MBT}=$ mercaptobenzothiazole PPD = p-phenylenediamine .

* Workers gave more than one positive reaction. ** irritant reaction 
Table (6): Distribution of the most important procedures \& things at the workplace that start and worsen CD.

\begin{tabular}{|l|c|}
\hline \multicolumn{1}{|c|}{ Procedures \& things } & CD N (\%) \\
\hline In car tinkers:(N=3) & $3(100.0)$ \\
- Hammering & $0(00.0)$ \\
- Welding & $0(00.0)$ \\
-Other aggravating factors & \\
\hline In car mechanics: (N=7) & $6(85.7)$ \\
-Friction with repaired parts, tar and engine oils & $2(28.6)$ \\
-Welding & $4(57.1)$ \\
-Other aggravating factors & \\
\hline In car painters:(N=6) & $5(83.3)$ \\
-Sanding/grinding of painting parts & $4(66.7)$ \\
-Cementing with pastes(masking) & $2(33.3)$ \\
- Mixing lacquers & $2(33.3)$ \\
-Spray painting & $3(50.0)$ \\
- Other aggravating factors & \\
\hline
\end{tabular}

Table (7): Risk factors of contact dermatitis among car repair workers.

\begin{tabular}{|c|c|c|c|c|c|}
\hline \multicolumn{3}{|c|}{ Risk factors } & $\begin{array}{c}\text { Car repair work- } \\
\text { ers with } \mathrm{CD} \\
\mathrm{N}=16\end{array}$ & $\begin{array}{l}\text { Car repair work- } \\
\text { ers without CD } \\
\quad \mathrm{N}=71\end{array}$ & OR ( 95\% CI) \\
\hline \multirow[t]{2}{*}{$\operatorname{Age}(y)$} & $<30$ & $\mathrm{~N}(\%)$ & $12(75.0)$ & $31(43.7)$ & \multirow[b]{2}{*}{$3.87(1.03-17.82)^{*}$} \\
\hline & $>30$ & $\mathrm{~N}(\%)$ & $4(25.0)$ & $40(56.3)$ & \\
\hline Smoking & & $\mathrm{N}(\%)$ & $11(68.8)$ & $27(38.0)$ & $3.59(1.00-14.44)^{*}$ \\
\hline \multicolumn{3}{|c|}{ Past history of atopy } & & & \multirow[b]{2}{*}{ 7.61(1.36-43.39)** } \\
\hline Positive & & $\mathrm{N}(\%)$ & $5(31.3)$ & $4(5.6)$ & \\
\hline \multicolumn{3}{|c|}{ Family history of atopy } & & & \multirow[b]{2}{*}{$4.92(1.00-22.88)^{*}$} \\
\hline Positive & & $\mathrm{N}(\%)$ & $5(31.3)$ & $6(8.5)$ & \\
\hline \multicolumn{3}{|c|}{ Duration of work(y) } & & & \multirow{3}{*}{$3.81(1.06-15.35)^{*}$} \\
\hline & $<10$ & $\mathrm{~N}(\%)$ & $5(31.3)$ & $45(63.4)$ & \\
\hline & $>10$ & $\mathrm{~N}(\%)$ & $11(68.7)$ & $26(36.6)$ & \\
\hline
\end{tabular}

$* \mathrm{P}<0.05 \quad * * \mathrm{P}<0.01$ 
Table (8): Changes in knowledge, attitude and behavior about contact dermatitis among car repair workers after the intervention study

\begin{tabular}{|c|c|c|c|c|}
\hline Knowledge \& attitude & $\begin{array}{c}\text { Car repair workers } \\
\text { Before } \\
\text { intervention } \\
\mathrm{N}=47 \\
\mathrm{~N}(\%)\end{array}$ & \begin{tabular}{|c|}
$\begin{array}{c}\text { Car repair workers } \\
\text { After }\end{array}$ \\
intervention \\
$\mathrm{N}=47$ \\
$\mathrm{~N}(\%)$
\end{tabular} & $\begin{array}{c}\text { MC- } \\
\text { NEMARS } \\
\text { Test }\end{array}$ & P-value \\
\hline $\begin{array}{l}\text { Knowledge: } \\
\text { Definition \& Causes: }\end{array}$ & $\begin{array}{l}22(46.8) \\
25(53.2)\end{array}$ & $\begin{array}{c}46(97.9) \\
1(2.1)\end{array}$ & 0.899 & $<0.001$ \\
\hline -Symptoms: & $\begin{array}{l}35(74.5) \\
12(25.5)\end{array}$ & $\begin{array}{c}44(93.6) \\
3(6.4)\end{array}$ & 9.3 & $<0.01$ \\
\hline -Risk factors: & $\begin{array}{l}20(42.6) \\
27(57.4)\end{array}$ & $\begin{array}{l}41(87.2) \\
6(12.8)\end{array}$ & 5.1 & $<0.001$ \\
\hline - Prevention: & $\begin{array}{l}26(55.3) \\
21(44.7) \\
\end{array}$ & $\begin{array}{c}44(93.6) \\
3(6.4) \\
\end{array}$ & 3.97 & $<0.001$ \\
\hline $\begin{array}{l}\text { Attitude \& behavior: } \\
\text {-Health seeking behavior }\end{array}$ & $\begin{array}{l}30(63.8) \\
17(36.2)\end{array}$ & $\begin{array}{l}41(87.2) \\
6(12.8)\end{array}$ & 12.1 & $<0.001$ \\
\hline $\begin{array}{r}\text {-Use of protective clothes: Yes } \\
\text { No }\end{array}$ & $\begin{array}{l}11(23.4) \\
36(76.6)\end{array}$ & $\begin{array}{l}40(85.1) \\
7(14.9)\end{array}$ & 2.5 & $<0.001$ \\
\hline
\end{tabular}


Table (9): Changes in symptoms \& signs of contact dermatitis among car repair workers after the intervention program.

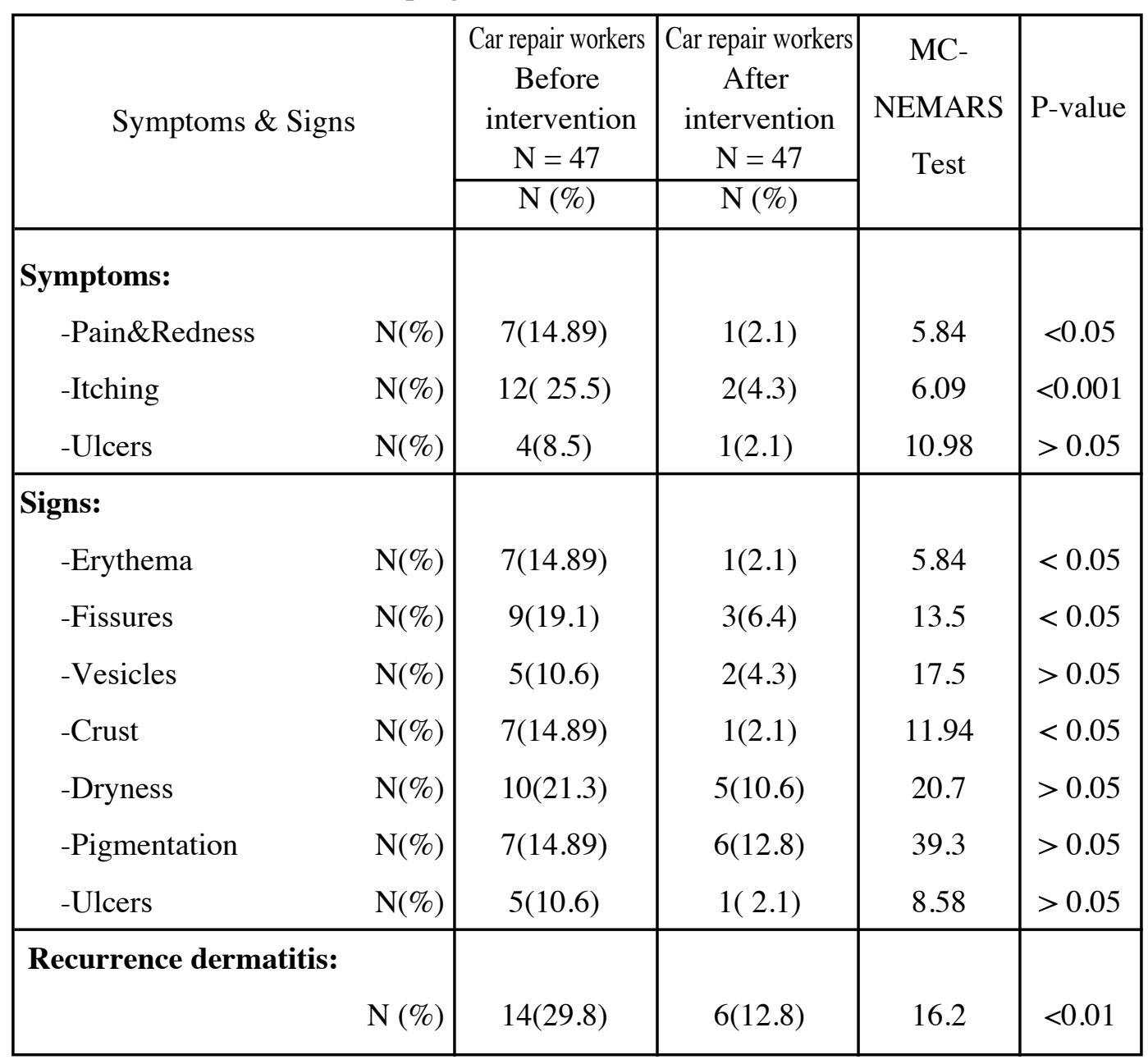




\section{Discussion}

Contact dermatitis is reported to represent about $90 \%$ of cases of occupational dermatoses and it is a common problem both in the workplace and in the general community as it has a poor prognosis with a high social and economic impact for both, individual and society $(9,29,30)$.

\section{The prevalence of contact dermatitis among the studied groups:}

In the present study, the total prevalence of OCD among car repair workers was significantly higher (18.4\%) when compared to their control booksellers. Also when the three investigated occupations in this study are considered, there are substantial differences. Car mechanics and car painters had a significant high risk of developing OCD $\{\mathrm{OR}(95 \% \mathrm{CT}), 7.74(1.57$ 49.07) and 6.35(1.21-41.43)\} respectively, while car tinkers were less affected \{OR (95\%CT), 2.81(0.35-22.06), and $\mathrm{P}>0.05$, as the highest prevalence of contact dermatitis was significantly detected among car mechanics $(24.1 \% \& \mathrm{P}<0.001)$, and car painters $(20.7 \% \& \mathrm{P}<0.01)$, when compared to their controls booksellers $(3.9 \% \&$ $\mathrm{P}>0.05)$.

Automobile repair workers are at risk of developing occupational dermatoses including dermatitis which was the common- est skin morbidity among them ${ }^{(31)}$. Moreover Funke et al. (2001) ${ }^{(22)}$ and Khalili et al. (1999)(32) reported in their studies that the prevalence of OCD among car repair workers was $15.3 \%$ and $13.1 \%$, while in other studies, it was $15 \%$ in car mechanics (33) and $11.9 \%$ in painters ${ }^{(34)}$.

It should be emphasized that just asking about contact dermatitis in a questionnaire does not reveal the true prevalence of OCD. Also dermatitis is a diagnosis which is not always easy for the patients to make themselves and the border-line between dermatitis and dry skin which proved to be the greatest problem for self-diagnosis. These reasons may be responsible for the difference in prevalence of OCD between our study and the other studies.

\section{Symptoms, signs, and site of contact dermatitis among car repair workers:}

The prevalence of $\mathrm{CD}$ symptoms and signs was significantly higher among car repair workers when compared to their controls booksellers. In accordance with other study(14), we reported that the clinical picture of $\mathrm{CD}$ is a polymorphic pattern of skin inflammation characterized by a wide variety of clinical features, including itching, redness, scaling and vesiculation.

About $16.1 \%$ of our car repair workers were complaining from recurrent dermati- 
tis in the last 12 months. This is in agreement with Suuronen et al.(2007)(12) who reported the same complaint in about $20 \%$ of the machinists and machine maintenance men. It has been suggested that the multifactorial origin of $\mathrm{CD}$ is responsible for the chronic course of the condition, which is often a combination of irritant , allergic and endogenous factors mainly atopic history(16).

In the present study, the most commonly affected areas with CD among car repair workers of this study were the fingers, webs and hands (81.3\%) and the wrists and forearms $(31.1 \%)$.

Working in an automobile manufacturing industry with high exposure to organic solvents carried higher risk of development hand eczema ${ }^{(20)}$. Many studies $(12,33,35)$ reported that, the hand or forearm dermatitis were mostly affected the machinists and machine maintenance men.

Also, Rietschel et al. (2002)(36), reported that the hands were the primary body part affected in $64 \%$ of allergic occupational cases and $80 \%$ of irritant occupational cases.

\section{ICD \& ACD among different occupa- tions in car repair shops:}

In the present study, the majority of car repair workers with $\mathrm{CD}(60 \%)$ were
ICD, while the other $40 \%$ were ACD.

Several studies revealed that, in occupations most at risk for allergic contact dermatitis as motor mechanics and painters, the prevalence of occupational ACD was less than $\operatorname{ICD}^{(37)}$. Also, Slodownik et al. (2006) ${ }^{(14)}$, reported $102 \mathrm{CD}$ cases among maintenance and clerical workers, 60 of them had ICD while 42 had ACD, of which $33(78.6 \%)$ were maintenance workers, mainly mechanics.

In contrast to our study, Rietschel et al. $(2002)^{(36)}$ reported that, $60 \%$ of the occupational $\mathrm{CD}$ cases were of allergic and $32 \%$ were of irritant origin. Also Suuronen et al.(2005)(38) reported that the number of allergic contact dermatitis (ACD) increased 3-fold in machinists.

\section{The important procedures \& things that start and worsen CD at the work place :}

In the present study, the most important procedures \& things at the workplace that start and worsen CD cases were hammering in car tinkers $(100.0 \%)$, friction with repaired parts, tar and engine oils in car mechanics(85.7\%), and sanding of painting parts $(83.3 \%)$ \& cementing the car body with pastes (masking) (66.7\%) in car painters respectively. While other aggravating factors at the workplace like wet- 
ness, frequent washing the hands with solvents and friction of the hands with anything, were also from the important things that worsen $\mathrm{CD}$ cases in car mechanics (57.0\%) and car painters (50.0\%) respectively.

These findings coincide with the results of other studies reporting that car mechanics, during activities, may be exposed to organic solvents $(39,40)$, epoxy resin in adhesives ${ }^{(41)}$, colophony and cutting oils (metalworking fluids) which were the most common causes of $\mathrm{CD}^{(12,42)}$.

Car repair workers are also exposed to toxic metals as chromium and chromates used in paints and pigments in the form of spray paint mist $(43,44,45)$.

Skin contact usually occurs when the worker handles parts, tools, and equipment covered with fluid or dips his hands into the fluid, floods the machine without the use of protective gloves or aprons ${ }^{(46)}$ and dermal exposure to organic solvents as toluene, acetone, and xylene can defat the skin ${ }^{(35)}$ and induce changes in the skin's barrier function ${ }^{(47)}$ and, thereby, increase the uptake of these solvents by the body (35). Also friction against the skin for example, from operating grinding machines and other equipment, can abrade or scrape away the skin. This can diminish the protective action of skin against allergens ${ }^{(46)}$.

In the current study nickel sulphate accounted for most positive patch test reactions 3/9 ( 2 car mechanics and 1 car painters), followed by colophony $2 / 9$, epoxy resin 2/9, potassium dichromate $1 / 9$, and p-phenylenediamine 1/9 in both car mechanics and painters. None of the nickel sensitive workers were regularly wearing jewellery. One explanation for the high prevalence of nickel allergy was the common use of nickel plated tools and pigments among these workers. So, the use of nickel-plated tools should be avoided in car mechanics where skin exposure to irritants promotes sensitization. Several allergens in the standard series also found in the work environment of car repair workers e.g., colophony, epoxy resin, chromium, and probably p-phenylenedia-mine. Other allergens can be found in this environment e.g. rubber, cobalt, ethylenediamine $^{(24,48)}$. Allergies to other different allergens in test panels were uncommon, as the prevalence of sensitivity to an individual allergen depends not only on the intrinsic allergenicity of the compound but also on the level of worker exposure to the allergens, which may vary from one workplace to other. Moreover, the number of 
car workers patch tested was small as we depend on the clinically diagnosed cases at the time of the study and not on the history of previously affected cases .

In agreement with our results Meding et al. (1994) ${ }^{(48)}$ reported 35/105 (33\%) of car mechanics series who reported hand eczema on some occasion in the previous 12 months had a total of 51 positive patch test reactions, all to substances in the standard series. The most frequent reactions were to thimerosal, nickel and colophony.

Vermulen et al. $(2000)^{(24)}$, reported that, the frequent causes of occupational allergic contact dermatitis are rubber chemicals, chromates and epoxy resins, while detergents, cutting oils, organic solvents and mechanical friction have been shown to elicit irritant contact dermatitis.

\section{Risk factors associated with CD:}

In this study, younger car repair workers (3.2 years), who smoke and work for more than 10 years had a significant high risk to develop CD when compared to older ones, non smokers and those who work for 10 years or less respectively \{OR $(95 \% \mathrm{CI})$ were 3.87 (1.03-17.82), 3.59 (1.00-14.44), and 3.81(1.06-15.35) respectively\}. In agreement with this study, Montnemery et al. (2005)(49), found that age was inversely related to the 1-year prevalence of hand eczema and the highest value was detected among those aged 2029 years. Moreover it was reported that increased prevalence of occupational contact dermatitis was associated with work experience $10-14$ years ${ }^{(32)}$.

While, in contrast to the present study, Sprince et al. (1996)(50) and Khalili et al. (1999) ${ }^{(32)}$, reported in their studies among automobile production machine operators and repair workers in the vehicleworkshop respectively, that increasing worker age was one of the risk factors which significantly associated with CD. Also a significant relationship was found between the occurrence of hand eczema and employment for less than 14 years as a car mechanic ${ }^{(33)}$.

In this study, a high prevalence of smoking with $\mathrm{CD}$ was observed. The influence of smoking on cell-mediated immunity is still obscure. Some studies ${ }^{(31,50)}$, found that smoking was independent risk factor for hand eczema. However, a recent Danish study found a significant association between contact allergy and smoking, with a dose-response relationship ${ }^{(51)}$. Further investigations into the possible mechanisms of this connection are required. 
Atopic disposition is the best known endogenous factor plays an important role in the aetiology of $\mathrm{CD}^{(30)}$. In our study, an atopic background is found up to $31.3 \%$ in workers with CD. Those workers had a significant high risk to develop CD more than those without past history of atopy.

In consistent with the present work, Dickel et al.(2003)(11) and Cvetkovski et al. (2005) ${ }^{(52)}$ found that $16 \%$ and $39 \%$ of atopic dermatitis had occupational CD. Other studies also suggest that for atopic individuals the probability that an occupational dermatitis will develop is increased by up to threefold $(19,53,54)$ and other reported that atopy is associated with severity of $\mathrm{CD}^{(55)}$. A possible explanation may be through increased allergen penetration through damaged eczematous skin in subjects with $\mathrm{AD}$ and thus increased risk of sensitization.

In contrast to this study, Meding $(1990)^{(4)}$ found that the childhood dermatitis reported in his study workers, had no significant effect on OCD.

In addition to the risk factors, car repair workers with family history of atopy had a significant high risk to develop CD. Khalili et al (1999) ${ }^{(32)}$ reported that OCD was significantly associated with positive family history of atopy and past history of skin disease.

\section{Skin care education intervention pro- gram results:}

This study demonstrates the importance of worker education as a tool for primary prevention of $\mathrm{CD}$. Evaluation after the five months of intervention study revealed a significantly higher knowledge level about CD causes, risk factors, prevention, change in the attitude and behavior evidenced by good health seeking behavior in the form of safe work practice, skin care and use of protective gloves compared to before the intervention. Also the prevalence of most skin symptoms reported by the workers and the clinically evaluated signs after the intervention study were significantly reduced than before the intervention study, although there is no change in the number and nature of hazardous materials handled before, during and after the program..

Previous study(23), also reported a significant, higher information level, change in behavior and less skin signs as evaluated clinically in the intervention group compared to the control group but in contrast to this study, they found no significant difference for self reported skin prob- 
lems. The introduction of skin protection programs in workplaces is an important element in the prevention of occupational contact dermatitis. This program was reported to change behavior and decrease skin symptoms in wet occupations $(2,56)$.

Educational efforts should promote awareness and identify work activities that would expose workers to allergens and irritants. Job training should also teach recognition of early signs and symptoms of contact dermatitis, proper use of protective clothing and barrier creams as well as personal and environmental hygiene $(57,58)$.

Koch $(2001)^{(59)}$ emphasized that the critical factors in the management of occupational contact dermatitis are recognition of clinical features, knowledge of allergens and irritants present in different occupational fields and knowledge of suitable protection

\section{Conclusion}

Car repair workers are at high risk to occupational contact dermatitis attributed to exposure to various chemicals at work. Young age, smoking, atopy and duration of work are found to be risk factors for contact dermatitis. Intervention development research is an essential prerequisite of any study that attempts to determine whether specific interventions prevent work related injury and illness or not. Our intervention was successful with respect to information level (knowledge), behavior, and clinical symptoms and it is concluded that this study demonstrates the importance of skin care education program as a tool for primary prevention of $\mathrm{CD}$ and control of exposure to substances hazardous to the skin.

\section{Recommendations}

More studies-ideally long-term largescale studies are needed to investigate the cost-effectiveness of that skin protection programs. Implementation of a skin care program as part of an occupational health and safety management system is recommended as a prophylactic measure for employees in risky occupations. It is important that the information in the program is comprehensible to the workers, training materials such as video and poster presentations may be effectively used and the important of the pre-employment counseling of atopic patients before exposure to chemicals.

\section{Acknowledgement}

The authors would like to thank all of the workers included in the present study 
for their cooperation and help.

\section{References}

1-English J.(2004): Current concepts of irritant dermatitis. Occup Environ Med ;61: 722-726.

2-Held E., Mygind K., Wolff C. et al.,(2002): Prevention of work related skin problems: an intervention study in wet work employees. Occup Environ Med; 59: 556-561.

3- Alomar A.(1994): Occupational skin diseases from cutting fluids. Dermatol Clin; 12:537-546.

4-Meding B.(1990): Epidemiology of hand eczema in an industrialized city. Acta Derm Venereol ; 153(suppl): 1-43.

5-Halkier-orensen L.(1996):Occupational skin diseases. Contact Dermatitis ;3 (suppl):1-12.

6-Leino-Arjas P., Liira J., and Mutanen P.(1999): Predictors and consequences of unemployment among construction workers: prospective cohort study. BMJ;4:600-5

7-Cherry N., Meyer J.D., and Adisesh A.(2000) Surveillance of occupational skin disease: EPIDERMA and OPRA. Br J Dermatol;142: 1128-34.

8-Sen D., McElvenny D., and Thomas R. (2001) : Self-reported skin problems among physical processors in the chemical industry in Great Britain. Occp Med ; 51 (1) : 12-24.

9-Leggat P.A., and Smith D.R.(2006): Dermatitis and aircrew. Contact Dermatitis;54(1):1-4

10-Brown J.A.(2007): Allergic contact dermatitis High risk jobs. Coated from, www.haz-map.com

11-Dickel H., Bruckner T.M., Schmidt A., et al.,
(2003): Impact of atopic skin diathesis on occupational skin disease: Incidence in a working population. J invest dermatol; 121(1):37-40.

12-Suuronen K., Jolanki R., Luukkonen R. et al., (2007): Self-reported skin symptoms in metal workers. Contact Dermatitis Published article online: 12 .

13-Diepgen T.L.,(2004): Minisymposium 10. Epidemiology of occupational dermatitis. Epidemiology and prevention of occupational contact dermatitis. Occup Environ Med; 61:73.

14-Slodownik D.,Wohl Y., Mansura A. et al., (2006): Allergic contact dermatitis among maintenance and clerical workers in a military population .Contact Dermatitis ; 55(6): 335-337.

15-White I.R., (1996): ABC of work related disorders: Occupational dermatitis. BMJ; 313: 487489.

16-Hogan D., May J., Belsito D. et al.,(2007): Contact Dermatitis, Allergic. Exp Dermatol Jun; 15(6): 432-440.

17-Winker C., and Turner P.J.(1992): Solvent exposure and related work practices amongst apprentice spray painters in automotive body repair workshops. Ann Occup Hyg ; 36 (4): 385-394.

18- Meding B.(2003): Epidemiology of nickel. J Environ Monit ; 5: 188-189.

19-Heron R.J.L.(1997): Worker education in the primary prevention of occupational dermatoses. Occup Med ; 47(7): 407-410.

20-Kristensen O.(1992): A prospective study of the development of hand eczema in an automobile manufacturing industry. Contact Dermatitis ;26 
(5):341-345.

21-Dean A.C., Dean J.A., Coulombeir D., et al., (1994): Epi-info version 6: a word processing data base and statistic programs for epidemiology on microcomputers. Center for Disease Control. Atlanta, Georgia, USA.

22-Funke U., Fartasch M., and Diepgen T.L.,(2001): Incidence of work-related hand eczema during apprenticeship: first results of a prospective cohort study in the car industry. Contact Dermatitis ;44 (3):166-172.

23-Susitaival P., Flyvholm M.A., Meding B. et al., (2003): Nordic occupational skin questionnaire (NOSQ-2002):a new tool for surveying occupational skin diseases and exposure. Contact Dermatitis;49(2):70-76

24-Vermeulen R., Kromhout H., Bruynzeel D.P., et al.,(2000): Ascertainment of hand dermatitis using a symptom-based questionnaire: applicability in an industrial population. Contact Dermatitis; 42: 202-206.

25-Fisher Tand Maiback HI.,(1984):The thin layer rapid use epicutaneous test (TRUE- test) ,a new patch test method with high accuracy .Br J Dermatol ;112:63-68.

26-Wilkinson D.S., Frgert S., Magnusson B. et al., (1970): Terminology of contact dermatitis. Acta Derm Verereol; 50: 287-292.

27-Macan J., Kanceljak-Macan B. and MilkoviKraus S .(2002): Pre-employment evaluation of atopy and contact dermatitis. Arch Hig Rada Toxicol; 53:119-124.

28-Norusis M.(1997): Statistical Package for Social
Science(SPSS) base 9.0 for windows users guide. Chichago IL: SPSS.

29-Nixon R., Frowen K., and Moyle M.(2005): Occupational dermatoses, Australian Family Physician; 34(5): 327-333.

30-Diepgen T. L., Agner T., Aberer W. et al., (2007): Management of chronic hand eczema. Contact Dermatitis. doi: 10,1111/j.1600-05 36.01179.x

31- Joshi M.P., Zodpey S.P., Bhatkule P.R. and Vasudeo N.D. (1997): Contact dermatitis in automobile repair workers. Indian J Dermatol; 42 (2): 65-67.

32-Khalili M.I.,Dhaise B.A., Abbossi M.M. et al., (1999): Contact dermatitis in auto repair workers. Saudi Med J ;20(3): 236-240.

33-Moen B.E., Hollund B.E., and Torp S.,(1995): A descriptive study of health problems on car mechanics. Occup Med ;45: 318-322.

34-Park J.B., Lee K.J., Jang J.Y., et al.,(1997): Skin diseases of male workers in painting workplace. Korean J Prev Med ;30(4):830-839.35Rademaker M. (2000): Occupational epoxy resin allergic contact dermatitis. Australas J Dermatol; 41(4): 222-224.

36-Rietschel R.L., Mathias C.G., Fowler J.F.et al., (2002): Relationship of occupation to contact dermatitis : evaluation in patients tested from 1998 to 2000. Am J Contact Dermat;3(4): 170176.

37-Skoet R., Olsen J., Mathiesen B., et al.,(2004): A survey of occupational hand eczema in Denmark. Contact Dermatitis;51(4):159-166. 
38-Suuronen K., Aalto-Korte K., Piipari R. et al., (2005): Occupational dermatitis and allergic respiratory diseases in Finnish metalworking machinists. Occup Med 57(4):277-283.

39-Heitbrink W.A., Cooper T.C., Edmonds M.A. et al.,(1993): In-Depth Survey Report: Control technology for autobody repair and painting shops coated from, http://www.osha.org

40-International Agency for Research on Cancer (1998): Occupational exposures in paint manufacture and painting; 47: $329 . \quad \mathrm{http} / /$ www.inchem.org/documents/iarc/vol47/47-

13.html

41-Bray P.G. (1999): Epoxy resins. Occupational Medicine STAR 14(4): 743.

42-NIOSH (1998): What you need to know about occupational exposure to metalworking fluids coated from, http://www.cdc.gov/niosh/ homepage.htm

43-Sastre J., and Quirce S.(2007): Sensitizing agents of occupational asthma, hypersensitivity pneumonitis and eosinophlic bronchitis. Allergic Diseases Resource Center Coated from, http:// www.worldallergy.org/professional/allergic_diseases_center/occupational_asthma/

44-Lasse I., Tuula E., Kristiina A. et al.,(1999): Occupational allergic contact dermatitis from unsaturated polyester resin in a car repair putty. Internat J Dermatol; 38(6): 447-452.

45-Kanerva L., Elsner P., Wahlberg J.E. et al., (2004):Handbook of Occupational Dermatology. NewYork : Springer-Verlag P104.

46-Canadian Centre for Occupational Health and
Safety(CCOHS)(1997-2006): Occupational contact dermatitis, Allergic contact dermatitis. Contact Dermatitis. Coated from, http:// www.ccohs.ca/oshanswers/diseases allergicderm.

47-Abrams K., Harvell J.D., Shriner D., Wertz P., Maibach H., Maibach H., and Rehfeld S.J. (1993): Effect of Organic Solvents In Vitro on Human Skin Water Barrier Function. J. Invest. Dermatol. 101: 609-613.

48-Meding B., Barregard L. and Marcus K. (1994) : Hand eczema in car mechanics . Contact dermatitis ;30 : 129-134.

49-Montnemery P., Nihlen U., Lofdahi C.G. et al., (2005): Prevalence of hand eczema in an adult swedish population and the relationship to risk occupation and smoking. Acta DermatoVenereologica; 85(5) : 429-432.

50-Sprince N.L., Palmer J.A., Popendorf W. et al., (1996): Dermatitis among automobile production machine operators exposed to metalworking fluids. Am J Ind Med;30(4):421-429.

51-Linneberg A., Nielsen N. H., Menné T. et al., (2003). Smoking might be a risk factor for contact allergy. J Allergy Clin Immunol ;111: 980984.

52-Cvetkovski R. S., Rothman K.J., Olsen J. et al., (2005): relation between diagnosis on severity, sick leave and loss of job among patients with occupational hand eczema. Br J Dermatol ; 152: 93-98.

53-Rystedt I. (1985): Work-related hand eczema in atopics. Contact Dermatitis; 12: 165-171. 
54-Shmunes E.(1986): The role of atopy in occupational skin disease. Occup Med State Art Rev ; 1: $219-228$

55-Keegel T., Erbas B., Cahill J. et al., (2007): Occupational contact dermatitis in Audtralia: diagnostic and management practices, and severity of worker impairment. Contact Dermatitis; 56 (6): $318-354$

56-Agner T., and Held E.(2002): Skin protection programmes. Contact Dermatitis; 46: 253-256.
57-Mathias C.G.(1990): Prevention of occupational contact dermatitis. Journal of American Academy of Dermatology, 23(4): 742- 745.

58-Hasniza B.A., Ruslibn B.N., Winn T. et al., (2003): A study of knowledge, attitude and practice on contact dermatitis among hospital cleaners in Kota Bharu Kelantan. NCD Malaysia,2 (4): 15-18.

59-Koch P. (2001): Occupational contact dermatitis. Recognition and management. Am J Clin Dermatol; 2:353-65. 